\title{
Tissue Factor-Derived Microparticle
}

National Cancer Institute

\section{Source}

National Cancer Institute. Tissue Factor-Derived Microparticle. NCI Thesaurus. Code C120029.

A small, membrane bound vesicle circulating in the blood that was shed by a cell that expresses the coagulation protein, tissue factor (factor III). The presence of microparticles with tissue factor in the plasma of cancer patients is associated with an increased risk for venous thrombosis. 